\title{
Hierarchical Linear Modeling Application in Analyzing Occupational Injuries Related Factors for Nurses in Taiwan
}

\author{
Min-Hui $L^{1,2}{ }^{1}$, Yu-Lung Wu ${ }^{3}$, Fu-I Hou ${ }^{4,5}$ and Wan-Yun Huang ${ }^{1,5^{*}}$ \\ ${ }^{1}$ Department of Physical Medicine and Rehabilitation, Kaohsiung Veterans General Hospital, Taiwan \\ ${ }^{2}$ Graduate Institute of Aerospace and Undersea Medicine, National Defense Medical Center, Taiwan \\ ${ }^{3}$ Department of Information Management, I-Shou University, Taiwan
}

${ }^{4}$ Evergreen Marine Corporation, Taiwan

${ }^{5}$ Department of Information Engineering, I-Shou University, Taiwan

*Corresponding author: Wan-Yun Huang, Ph.D., Department of Physical Medicine and Rehabilitation, Kaohsiung Veterans General Hospital; Department of Information Engineering, I-Shou University, No.386, Dazhong 1st Rd., Zuoying Dist., Kaohsiung City 81362, Taiwan (R.O.C.), Tel: $+886-73422121$

\begin{abstract}
Nurses are prone to occupational injuries due to the nature of their roles in the medical care environment. To narrow the gap in literature, this research analyzes the relevant individual- and hospital-level factors of occupational injuries suffered by nursing personnel in Taiwan by targeting those with occupational injury records in the 2013 National Health Insurance Research Database. A two-level research model consisting of the individual demographic data, hospital category and types, and individual medical expenditures with three hypotheses was formulated. Descriptive statistics were performed and four hierarchical linear models were established and analyzed using SPSS 20.0 and HLM 7.01. The result showed that 5,599 nursing personnel had outpatient treatments for occupational injuries, and made more than three medical visits, with a corresponding US\$124 in medical expenditure per person on average in 2013. Specifically, post-operative shock was the major diagnosis among the top ten injuries suffered by nursing personnel. The results of the random regression coefficient model and intercept model indicate that the age of nursing personnel at the individual level and the public/private sector type at the hospital level have positive effects on the individual medical expenditures of nursing personnel. It is recommended that the hospital management should reinforce training of nursing personnel to reduce the occurrence of occupational injuries and corresponding medical expenditures, especially for private hospitals and younger nurses.
\end{abstract}

\section{Keywords}

Nurses, Medical expenditures, Occupational injuries, National Health Insurance Research Database, Hierarchical linear modeling

\section{Introduction}

Nurses in Taiwan work an average of 9.5 hours per day [1] and due to such long working hours they are therefore highly prone to a number of occupational injuries and occupational diseases. According to Article 2 of the 2013 Occupational Safety Act in Taiwan, occupational accidents refer to diseases, injuries, disabilities, or deaths of workers caused by building structures, machinery, equipment, raw materials, chemicals, gas vapor, dust in the workplace, or other work activities [2]. Because of the nature of nursing work, personnel in this profession are highly prone to certain injuries, such as lower back pain $[3,4]$ and needlestick incidents, which are reported worldwide [5-9], or diseases, such as breast cancer [10]. Hence, the occupational safety of the nursing profession has become an important research topic.

The occurrence of occupational diseases and injuries translates to an increase in medical expenditures. In 2013, 297 cases received occupational injury benefits from healthcare and social work services labor insurance in Taiwan, which increased to 311 cases in 2014. The corresponding payment appears to be a $9.2 \%$ increase in the medical benefits given due to occupational injuries [11,12].

It is important to analyze the proportions and relevant factors of occupational diseases and occupational inju-

Citation: Min-Hui L, Yu-Lung W, Fu-I H, Wan-Yun H (2018) Hierarchical Linear Modeling Application in Analyzing Occupational Injuries Related Factors for Nurses in Taiwan. Int Arch Nurs Health Care 4:101. doi.org/10.23937/2469-5823/15100101

Accepted: October 13, 2018: Published: October 15, 2018

Copyright: (c) 2018 Min-Hui L, et al. This is an open-access article distributed under the terms of the Creative Commons Attribution License, which permits unrestricted use, distribution, and reproduction in any medium, provided the original author and source are credited. 
ries among nursing personnel for their health concerns, as well as the change of management or policy by hospital executives or the National Health Insurance Administration in Taiwan. Hierarchical Linear Model (HLM), is an analytical technique for hierarchical data. This research includes individual occupational injuries and diseases due to personal factors or work place (hospital) factor, or both. In view of the nested structure between individual (nurses) and group (hospital) constructs, due to the mediating impact of group level on individual level. Specifically, the National Health Research Database (NHRI) and Hierarchical Linear Modeling (HLM) are considered for the following reasons. First, currently, since no study has used the NHRI to explore the medical expenditures and financial burden arising from occupational diseases and injuries of nursing personnel, this study uses the $2013 \mathrm{NHRI}$ to analyze the kinds of treatments sought by nursing personnel, the types of diagnoses of occupational diseases and injuries, medical health insurance payments, and the proportion of occurrence. Second, HLM generally divides the data structure into two levels, such as nurse personnel and hospital, and then analyzes the causal effects of variables at same or different levels as well the moderations on the relationship between variables at different levels [13]. Therefore, this study applies hierarchical linear models to analyze the relevant factors and other effects of occupational diseases and injuries occurring among nursing personnel with corresponding hospital differences using the NHRI database.

\section{Methods}

The research approach uses an observational method, which adopts the NHRI data from the National Institute of Health in 2013 and targets nursing personnel suffering from occupational diseases or injuries.

Large computerized databases derived from this system by the National Health Insurance Administration, Taiwan and maintained by the National Health Research Institutes, Taiwan, are provided to scientists in Taiwan for research purposes. Data in the National Health Insurance Research Database (NHIRD) that can be used to identify patients or care providers, including medical institutions and physicians, is scrambled before being sent to the National Health Research Institutes for database construction and is further scrambled before being released to each researcher. The project obtained the KAOHSIUNG VGH Institutional Review Board through the special research project of Kaohsiung Veterans General Hospital (project number: VGHKS15-CT5-06). Sources of data include age, gender, job position, and place of hospital practice from the Registry for Medical Personnel (PER). From data on Occupational Diseases and Occupational Injuries (OC), the study obtained outpatient prescriptions from Ambulatory Care Expenditures by Visits $(C D)$, putting it under a payment category with a value of either 1 (occupational injury) or 2 (occupational disease). Data for the registered nurse (RN) or licensed practical nurse (LPN) who is working in the hospital were sampling from Taiwan's National Health Insurance Research Database (NHIRD) in Taiwan. Nursing personnel can be categorized into Registered Nurse (RN) or Licensed Practical Nurse (LPN) while age is categorized into below 30, 31-40, 41-50, or 51 and above. Based on the scale of operations, hospitals can also be categorized into medical center, metropolitan hospital, local community hospital, or clinic. The sector type for hospitals is either public or private.

\section{Documentary Analysis}

This study uses HLM to conduct analysis by dividing the data structure into two levels, nurse personnel at the individual level and hospital at the overall level, and analyzing the causal effects and moderations within the nest model [14]. Consequently, this study first uses SAS 9.3 to convert the NHRI text files before using SPSS statistical software 20.0 to analyze the descriptive statistics and HLM 7.01 to establish relevant hierarchical linear models for regression analyses. In the proposed HLM research model, the individual level covers the medical expenditures of nursing personnel for occupational disease and injury as well as demographic variables such as age, gender, and job position (RN or LPN). The model for the over-

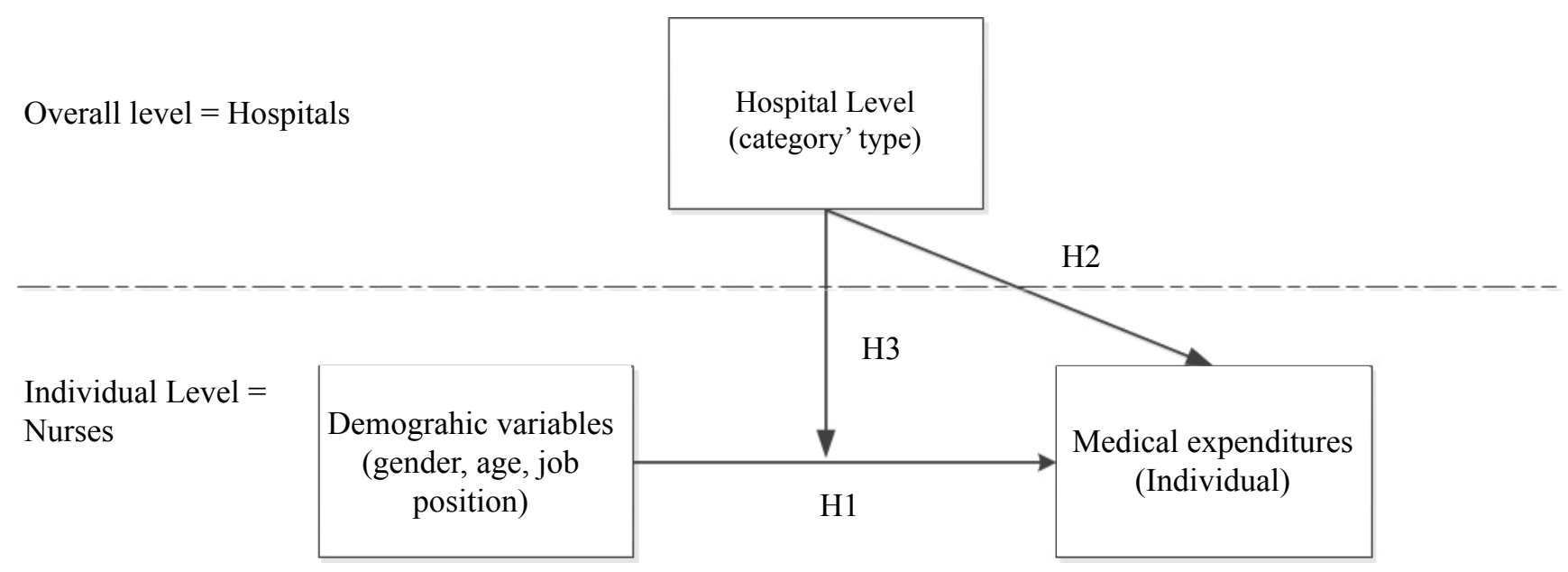

Figure 1: HLM research model. 
all level was established according to the hospital's scale of operations and sector type. The proposed research model was formulated to respond to the research objectives with the considered variables, as shown in Figure 1, with the corresponding proposed hypotheses:

Hypothesis 1: The demographic variables at the individual level (gender, age, and job position) have positive effects on the individual medical expenditures of nursing personnel.

Hypothesis 2: The hospital category and type at the overall level have positive effects on the individual medical expenditures of nursing personnel.

Hypothesis 3: The hospital category and type at the overall level have moderating effects on the relationship between demographic variables at the individual level and the individual medical expenditures of nursing personnel.

\section{Results}

Four tables of relevant descriptive statistics are briefly summarized in this section. As shown in Table 1 , in 2013, Taiwan had 176,414 nursing personnel, 141,968 $(80.4 \%)$ of which were registered nurses and 173,651 (98.4\%) of which were female. The average age was 34 , with the largest age group $(73,839$, equivalent to $41.8 \%)$ being between the ages of 31 and 40 . At the hospital level, metropolitan hospitals accounted for the largest category $(57,522$ individuals, equivalent to $32.6 \%)$. In terms of sector type, private hospitals had the highest number of nursing personnel $(128,261$ individuals, equivalent to $72.7 \%$ ).

As shown in Table 2, data from the 2013 NHRI shows that 5,599 nursing personnel had outpatient treatments for occupational injuries, and made a total 17,742 medical visits, of which 4,822 registered nurses made 14,222

Table 1: Descriptive statistics of the 2013 nursing personnel.

\begin{tabular}{|c|c|c|c|c|c|c|c|c|c|c|}
\hline \multicolumn{5}{|c|}{ Individual level } & \multicolumn{6}{|c|}{ Overall level } \\
\hline Variable & Category & $\begin{array}{l}\text { Sub- } \\
\text { category }\end{array}$ & Subtotal (\%) & Total (\%) & Variable & Category & $\begin{array}{l}\text { Sub- } \\
\text { category }\end{array}$ & Number & $\%$ & $\begin{array}{l}\text { Total } \\
(\%)\end{array}$ \\
\hline \multirow{2}{*}{$\begin{array}{l}\text { Nursing } \\
\text { personnel }\end{array}$} & \multirow[t]{2}{*}{ Nursing } & $\mathrm{RN}$ & $141,968(80.4)$ & \multirow[t]{2}{*}{$176,414(100)$} & \multirow{8}{*}{$\begin{array}{l}\text { Hospital } \\
\text { category }\end{array}$} & \multirow[t]{2}{*}{ Medical centers } & RN & 44,665 & 31.5 & \multirow{2}{*}{$\begin{array}{l}47,930 \\
(27.2)\end{array}$} \\
\hline & & LPN & $34,446(19.6)$ & & & & LPN & 3,265 & 9.5 & \\
\hline \multirow[t]{4}{*}{ Gender } & \multirow[t]{2}{*}{ Female } & RN & 139,478 & \multirow[t]{2}{*}{$173,651(98.4)$} & & \multirow{2}{*}{$\begin{array}{l}\text { Metropolitan } \\
\text { hospitals }\end{array}$} & RN & 50,571 & 35.6 & \multirow{2}{*}{$\begin{array}{l}57,522 \\
(32.6)\end{array}$} \\
\hline & & LPN & 34,173 & & & & LPN & 6,951 & 20.2 & \\
\hline & \multirow[t]{2}{*}{ Male } & $\mathrm{RN}$ & 2,490 & \multirow[t]{2}{*}{$2,763(1.6)$} & & \multirow{2}{*}{$\begin{array}{l}\text { Local community } \\
\text { hospitals }\end{array}$} & RN & 22,268 & 15.7 & \multirow{2}{*}{$\begin{array}{l}31,580 \\
(17.9)\end{array}$} \\
\hline & & LPN & 273 & & & & LPN & 9,312 & 27 & \\
\hline \multirow[t]{8}{*}{ Age } & \multirow[t]{2}{*}{$<30$} & RN & 46,577 & \multirow[t]{2}{*}{$51,911(29.4)$} & & \multirow[t]{2}{*}{ Clinics } & RN & 24,464 & 17.2 & \multirow{2}{*}{$\begin{array}{l}39,382 \\
(22.3)\end{array}$} \\
\hline & & LPN & 5,334 & & & & LPN & 14,918 & 43.3 & \\
\hline & \multirow[t]{2}{*}{$31-40$} & $\mathrm{RN}$ & 59,788 & \multirow[t]{2}{*}{$73,839(41.8)$} & & \multirow[t]{2}{*}{ Public hospital } & RN & 42,655 & 30 & \multirow{2}{*}{$\begin{array}{l}48,153 \\
(27.3)\end{array}$} \\
\hline & & LPN & 14,051 & & & & LPN & 5,498 & 16 & \\
\hline & \multirow[t]{2}{*}{$41-50$} & RN & 27,436 & \multirow[t]{2}{*}{$34,146(19.3)$} & \multirow[b]{2}{*}{$\begin{array}{l}\text { Sector } \\
\text { type }\end{array}$} & \multirow[t]{2}{*}{ Private hospital } & RN & 99,313 & 70 & \multirow{2}{*}{$\begin{array}{l}127,261 \\
(72.7)\end{array}$} \\
\hline & & LPN & 6,710 & & & & LPN & 28,948 & 84 & \\
\hline & \multirow[t]{2}{*}{$>50$} & $\mathrm{RN}$ & 8,167 & \multirow[t]{2}{*}{$16,518(9.4)$} & & & & & & \\
\hline & & LPN & 8,351 & & & & & & & \\
\hline
\end{tabular}

RN: Registered Nurse; LPN: Licensed Practical Nurse.

Table 2: 2013 Medical expenditures of nursing personnel for occupational diseases and injuries.

Individual Level

\begin{tabular}{|c|c|c|c|c|c|}
\hline & Variable & $\begin{array}{l}\text { No. of individuals } \\
\text { (No. of Visits) }\end{array}$ & $\begin{array}{l}\text { Medical expenditure } \\
\text { sub-total US\$ (\%) }\end{array}$ & $\begin{array}{l}\text { Personal Medical } \\
\text { expenditure US\$ }\end{array}$ & Total US\$ (\%) \\
\hline \multirow[t]{2}{*}{ Nursing personnel } & Registered nurses & $4,822(14,222)$ & $563,191(81.4 \%)$ & 117 & \multirow[t]{2}{*}{$692,258(100 \%)$} \\
\hline & Licensed practical nurses & $777(3,520)$ & $129,067(18.6 \%)$ & 166 & \\
\hline \multirow[t]{2}{*}{ Gender } & Female & $5,438(17,223)$ & $675,056(97.5 \%)$ & 124 & \multirow[t]{2}{*}{$692,258(100 \%)$} \\
\hline & Male & $161(519)$ & $17,202(2.5 \%)$ & 107 & \\
\hline \multirow[t]{4}{*}{ Age } & $<30$ & $2,884(7,449)$ & $283,085(40.9 \%)$ & 98 & \multirow[t]{4}{*}{$692,258(100 \%)$} \\
\hline & $31-40$ & $1,951(6,634)$ & $261,758(37.8 \%)$ & 134 & \\
\hline & $41-50$ & $565(2,523)$ & $99,034(14.3 \%)$ & 175 & \\
\hline & $>50$ & $199(1,136)$ & $48,381(7 \%)$ & 243 & \\
\hline \multicolumn{6}{|l|}{ Overall Level } \\
\hline \multirow[t]{4}{*}{ Hospital category } & Medical centers & $1,695(4789)$ & $187,599(27.1 \%)$ & 111 & \multirow[t]{4}{*}{$692,258(100 \%)$} \\
\hline & Metropolitan hospitals & $2,211(6062)$ & $269,124(38.9 \%)$ & 122 & \\
\hline & $\begin{array}{l}\text { Local community } \\
\text { hospitals }\end{array}$ & $942(2864)$ & $112,476(16.2 \%)$ & 119 & \\
\hline & Clinics & $751(4,027)$ & $123,059(17.8 \%)$ & 164 & \\
\hline \multirow[t]{2}{*}{ Sector type } & Public hospitals & $1,039(2,792)$ & $132,732(19.2 \%)$ & 128 & \multirow[t]{2}{*}{$692,258(100 \%)$} \\
\hline & Private hospitals & $4,560(14,950)$ & $559,526(80.8 \%)$ & 123 & \\
\hline
\end{tabular}

New Taiwan Dollar (NT\$) with the exchange rate of US\$1 = NT\$30.8 as of September 18, 2018. 
Table 3: Relevant statistics of treatment categories by nursing personnel seeking treatment for occupational injuries.

\begin{tabular}{|l|l|l|l|}
\hline Category of Visits & $\begin{array}{l}\text { No. of } \\
\text { Individuals }\end{array}$ & $\begin{array}{l}\text { No. of } \\
\text { Visits }\end{array}$ & $\begin{array}{l}\text { Medical } \\
\text { Expenditures } \\
\text { US\$ }\end{array}$ \\
\hline Emergency Medicine & 1,514 & 1,606 & 127,070 \\
\hline Family Medicine & 1,283 & 2,143 & 71,858 \\
\hline Infectious Disease & 897 & 1,586 & 51,801 \\
\hline Physical Therapy & 758 & 4,150 & 175,371 \\
\hline Internal Medicine & 705 & 1,387 & 65,034 \\
\hline Orthopedics & 683 & 2,218 & 65,326 \\
\hline Gastroenterology & 471 & 942 & 37,770 \\
\hline Surgery & 466 & 920 & 26,169 \\
\hline Chinese Medicine & 179 & 1,264 & 27,906 \\
\hline Occupational Medicine & 143 & 269 & 6,964 \\
\hline Ophthalmology & 141 & 299 & 4,934 \\
\hline Plastic Surgery & 111 & 340 & 10,157 \\
\hline Neurosurgery & 98 & 190 & 7,378 \\
\hline Neurology & 49 & 162 & 6,508 \\
\hline Dermatology & 43 & 74 & 1,385 \\
\hline OB-GYN & 19 & 31 & 1,871 \\
\hline Urology & 15 & 18 & 611 \\
\hline EENT & 15 & 37 & 970 \\
\hline Psychiatry & 13 & 28 & 1,119 \\
\hline New Taiwan Dollar & & W & \\
\hline
\end{tabular}

New Taiwan Dollar (NT\$) with the exchange rate of US\$1 = NT\$30.8 as of September 18, 2018.

visits and 5,438 females made 17,223 visits. Occupational injuries primarily occurred in the below 30 age bracket (2,884 personnel making 7,449 visits). In 2013, medical expenditures for nursing personnel who sustained occupational disease and injury amounted to about US\$692 thousand, an average of US\$124 per person. The figure was US\$563 thousand for licensed practical nurses, which was considered a comparatively higher amount while for female nursing personnel, medical expenditures amounted to US\$675 thousand, exceedingly higher than their male counterparts. Furthermore, medical expenditures for occupational disease and injury sustained by individuals below 30 was the highest at US\$283 thousand.

As seen in Table 3 ranked by number of visits, for nursing personnel, emergency medicine was the medical field they sought the most treatment from, with medical expenditures amounting to about US\$127 thousand. This is followed by family medicine, with medical expenditures at US\$71 thousand, and infectious disease, with medical expenditures at US\$51 thousand. With the data from the clinical visits for occupational disease and injury showing that the number of people who visited was higher than the number of nursing personnel who sustained occupational injuries, it is evident that some nursing personnel may visit more than two medical categories after sustaining occupational disease and injury.

Table 4 shows the top 10 major occupational diseases and injuries of nursing personnel, the number of personnel seeking treatment, and the amount of medical expenditures. For registered nurses, post-operative shock was the major diagnosis when treatment was




Table 5: 2013 HLM results on the occupational injuries of nursing personnel.

\begin{tabular}{|c|c|c|c|c|}
\hline Parameter analysis & $\begin{array}{l}\text { Null model }^{a} \\
\text { Coeffi/S.E. }\end{array}$ & $\begin{array}{l}\text { Random coefficient } \\
\text { regression model (RCRM) } \\
\text { Coeffi/S.E. }\end{array}$ & $\begin{array}{l}\text { Intercepts-as- } \\
\text { outcomes model } \\
\text { (IAOM) Coeffi/S.E. }\end{array}$ & $\begin{array}{l}\text { Intercept- and slopes- } \\
\text { as outcome model } \\
\text { Coeffi/S.E. }\end{array}$ \\
\hline Intercept values & $3.892(0.198)^{* * *}$ & $-0.602(1.434)$ & $2.838(0.240)^{* * *}$ & $0.622(0.897)$ \\
\hline \multicolumn{5}{|l|}{ Individual level } \\
\hline Age & & $0.149(0.027)^{* * *}$ & & $0.144(0.026)^{*+* t}$ \\
\hline Gender & & $0.268(1.031)$ & & $0.294(0.327)$ \\
\hline Position & & $-0.572(0.531)$ & & $-0.837(0.362)^{*}$ \\
\hline \multicolumn{5}{|l|}{ Overall level } \\
\hline Sector type & & & $0.417(0.103)^{*+*}$ & $-0.509(0.605)$ \\
\hline Hospital category & & & $0.389(0.917)$ & $0.008(0.167)$ \\
\hline Group variance & 170.707 & 163.196 & 170.778 & 169.646 \\
\hline Deviance & 44707.972 & 44572.882 & 44697.764 & 44654.342 \\
\hline
\end{tabular}

a ${ }^{\prime} C 1=1.1534 / 1.1534+170.70783=0.007$ is considered as a low degree of correlation; ${ }^{*} p<0.05 ;{ }^{* *} p<0.01 ; *{ }^{* * *} p<0.001$.

sought, which was also the most common diagnosis made during medical visits and the one that costed the most, about US\$106 thousand. For licensed practical nurses, post-operative shock was also the major diagnosis when treatment was sought; it was the most common diagnosis made during medical visits and the one that costed the most, about US\$12 thousand.

This section summarizes the relevant testing results of the three hypotheses by HLM behind occupational diseases and injuries sustained by nursing personnel, as shown in Table 5. First, the null model was used to calculate the correlation coefficient within the group, and the degree of association between the dependent variables (medical expenditures) and the group was analyzed [15]. The formula for the intra-class correlation coefficient 1 (ICC1) is $\tau 00 /(\tau 00+\sigma 2)$, and the ICC1 value of $1.1534 / 1.1534+170.70783=0.02$ belongs to a low degree of association according to the range of low intensity association, $0.010 \leq \rho<0.059$, by Cohen (1988) [16]. That is, there is a relatively low but still significant difference between personal medical expenditures of nursing personnel among hospitals.

Second, the result of the random regression coefficient model indicates that the age of nursing personnel at the individual level has a positive effect on the individual medical expenditures of nursing personnel, which partially supports Hypothesis 1 . In a survey of 3,914 nursing personnel in Taiwan, the occurrence of musculoskeletal disorders (MSDs) was highest in the 20-24 age bracket and lowest in the above 60 group, which echoes the theory of the age of nursing personnel being one factor affecting occupational disease and injury [17]. In a study conducted on 1,489 nursing personnel by a Swiss university hospital, the occurrence of needlestick and sharps injuries was also higher among individuals between the ages of 16 and 25 [18].

Third, the results of the intercept model indicate that only the public/private sector type at the hospital level has a positive effect on the individual medical expenditures of nursing personnel, which also partially supports Hypothesis 2. This result is supported by an analysis of outpatient costs from the 2003-2009 health care databases in Taiwan, which concludes that medical personnel in private hospitals have a higher probability of experiencing occupational disasters than those in public hospitals [19]. In the literature, private and public hospitals in Taiwan have significant differences in many aspects, such as on efficiency [20], service quality [21], and physician-compensation arrangement [22].

Fourth, the results of the complete model point out that both hospital category and type at the hospital-level have no moderating effects on the individual-level relationship between the demographic variables and the personal medical expenditures of nursing personnel, which fails to support Hypothesis 3 [23].

\section{Discussion}

This study uses data from the $2013 \mathrm{NHRI}$ to look at the proportion of occupational injuries among nursing personnel as well as the relevant factors. At work, nurses often suffered lower back pain due to helping turn patients' bodies over in bed, needle stick incidents, breast cancer due to night shift rotations, and other occupational diseases. For example, an early investigation of 541 nurses in Taichung found that $46.02 \%$ of the subjects suffered lower back pain, of which $55.42 \%$ occurred within one year after the beginning of their nursing career [24]. Among the nursing personnel in Taiwan in 2013 , the proportion of occupational injury occurrences was $5,599 / 176,414=3.17 \%$, in which the proportion for registered nurses was $4,822 / 141,968=3.39 \%$ while for licensed practical nurses was $777 / 34,446=2.25 \%$, showing that the occurrence rate for registered nurses was relatively higher. In a survey conducted by the Canadian-based Occupational Health and Safety Agency for Healthcare (OHSAH), the annual rate of all injuries for full-time workers was 7.4\% [25], which is higher than that in our case. Another survey also shows that nursing personnel belong to the group of workers with the highest percentage of occupational injuries $(86 \%, 284 / 330)$ among medical personnel [26]. Consequently, there 
is a real need for exploration and improvement, given that nursing personnel are on the frontline of serving patients, but there are many existing factors causing occupational injuries in their work environment.

The proportion of occupational diseases and injuries occurring in female nursing personnel is 5,438/173,651 $=3.13 \%$, while the proportion in their male counterparts is $161 / 2,763=5.82 \%$, which indicates a higher occurrence rate for male nursing personnel. In terms of age, the proportion of occupational diseases and injuries occurring in individuals is $2,884 / 51,911=5.56 \%$ for those below $30,1,951 / 73,839=2.64 \%$ for those between 31 and $40,565 / 34,146=1.65 \%$ for those between 41 and 50 , and $199 / 16,518=1.2 \%$ for those above 50 . Results show that the younger the nursing personnel, the higher the proportion of occupational injury occurrence, but the older the age, the more personal medical expenses is used (Table 2). Possible reasons for this may include more extensive work experience and better occupational injury prevention training. However, a similar survey [27] of 680 medical and nursing personnel shows that the proportion of occupational injury occurrence was $77.3 \%$ for individuals with less than five years of working experience, $79.6 \%$ for those with 5 to 10 years of work experience, and $82.3 \%$ for those with more than 10 years of work experience, which contradicts the results of this study. A probable reason may be that individuals who seek treatment for light injuries may not inform their doctors that the injuries were sustained on the job. Hence, these injuries would not be recorded within NHRI as being occupational in nature.

At the hospital level, the proportion of occupational injury occurrence is $1,695 / 47,930=3.54 \%$ at medical centers, $2,211 / 57,522=3.84 \%$ at metropolitan hospitals, $942 / 31,580=2.98 \%$ at local community hospitals, and $751 / 39,382=1.91 \%$ at clinics. This shows that the proportion of occupational injury occurrences is the highest in nursing personnel working in metropolitan hospitals, followed by those working in medical centers. In terms of sector type, the proportion of occupational injury occurrence at public hospitals is $1,039 / 48,153=$ $2.16 \%$, lower than the proportion for nursing personnel at private hospitals, which is $4,560 / 128,261=3.56 \%$. Similar to the results of this study, the top occupational injuries of psychiatric nursing staff in Taiwan were musculoskeletal pain and numbness from lower back pain, and their coping strategy had statistically significant differences by public and private hospitals among other factors [28]. Studies have pointed out that stress and anxiety have a significant impact on the risk of WRMSDS [29]. A possible reason may be due to either nursing personnel in private hospitals working under higher pressure or to longer working hours. In the study by Liu, et al. and nurses in Taiwan to be overloaded in terms of both overtime and patient-nurse ratios, to recommend the Department of Health to stipulate a maximum patient-nurse ratio for each of hospitals' three daily shifts as a basic requirement of medical institutions [30].

In the $2013 \mathrm{NHRI}$, the major diagnosis for nursing personnel seeking medical treatment for occupational injury was post-operative shock $(n=1,704)$ with the proportion of occurrence being 1,704/176,414 $=0.97 \%$, followed by occupational injuries involving the musculoskeletal systems (icd9 $=710-739$ ) with a total of 616 registered nurses and 188 licensed practical nurses representing a proportion of occurrence of 804/176,414= $0.46 \%$. Literature supports similar results, such as an annual occurrence rate for musculoskeletal injury for fulltime workers of 5.9\% [25] as well as occurrence proportions of occupational injuries sustained by 160 nursing personnel in terms of lower back pain (35\%), neck pain (31.3\%), shoulder pain (25.2\%), and wrist pain (17.8\%) [31]. In 2013, medical expenditures for occupational diseases and injuries sustained by registered nurses amounted to about US\$563 thousand, while the figure for licensed practical nurses was about US\$129 thousand, totaling US\$692 thousand, which is a significant amount of health insurance resources being consumed, leading to an increase in medical expenditures [32].

By applying HLM to test the three hypotheses for the relevant factors of occupational disease and injury in nursing personnel, this research identifies that the age and job position at the individual level, as well as the sector type of the hospital they work in at the hospital level do increase their personal medical expenditures. Nevertheless, the hospital-level factors do not moderate the relationship between the demographic variables and personal medical expenditures. The partially validated Hypothesis 2 and non-validated Hypothesis 3 also confirm that the relatively low significant ICC estimate does reflect a weak need for the use of HLM regarding the type, public versus private, of hospital differences. In summary, Umesh, et al. clearly stated that nursing personnel should improve their awareness of occupational disease and injury and formulate improvement strategies to prevent the occurrence of occupational disease and injury and reduce the financial burden of medical expenditures arising from them [33]. This is particularly important to the administrators in private hospitals which have a higher occurrence rate than that of public hospitals according to the descriptive analyses above.

\section{Limitations and Further Study}

Two research limitations are briefly summarized as follows: First, not all nursing personnel who got sick or were injured on the job sought treatment, and thus the actual number of those with occupational injuries may be higher than what the HNRI data indicates. Second, the use of NHRI data is a form of secondary data analysis [34], and thus when interpreting the results, Type 1 error due to atomic fallacy [35] may be easily introduced by inferring the hospital-level analyses from the individual-level analyses. A supplementary study in the imme- 
diate future may apply actual survey questionnaires to collect data on items such as the nature of work, number of working hours, and specific job descriptions, for integrated analyses with the NHRI database to achieve more comprehensive analyses of relevant factors causing occupational injuries to nursing personnel.

\section{Conclusions}

The occurrence of occupational disease and injury is very common among nursing personnel. The study uses NHRI data to analyze the medical expenditures incurred due to occupational injuries, major diagnoses made during patient visitation, as well as the factors behind these injuries. By utilizing HLM to explore the relevant factors behind occupational injuries of nursing personnel, the study finds that the age and job position of nursing personnel as well as public or private type of affiliation can have a direct impact on occupational injuries. However, there is no significant moderating effect of hospital category or type on the relationship between demographic variables and personal medical expenses at the individual level, which may be due to the relatively small sample size in the 2013 NHRI database, compared to other countries. Even with weak hospital level influence, and only direct effect of public and private hospitals, all medical institutions should draft relevant policies for occupational safety and form occupational safety monitoring units. Furthermore, they should reinforce training of medical and nursing personnel to reduce the occurrence of occupational injuries, which would, in turn, decrease consumption of medical resources and improve the quality of work and life of nursing personnel, especially for the larger number of private hospitals with higher occurrence rates.

\section{Funding}

The author(s) received no financial support for the research, authorship, and/or publication of this article.

\section{Acknowledgements}

We thank Professor Ya-Hui Yang and all those involved in this study.

\section{Conflicts of Interest}

The author(s) declared no potential conflicts of interest with respect to the research, authorship, and/or publication of this article.

\section{References}

1. Chang TH, Chang SP, Chen NW (2013) The relationships between nurses' work hours and job satisfaction. Hungkuang Journal 69: 12-25.

2. http://www.mol.gov.tw/topic/3070/14692/

3. Hou JY, Shiao JS (2006) Risk factors for musculoskeletal discomfort in nurses. J Nurs Res 14: 228-236.

4. Ko HW, Juan C W, Chang HJ (2011) Lower back pain related factors in nursing staff and caregivers. Show-Chwan Med Journal 10: 69-80.
5. Gershon RR, Qureshi KA, Pogorzelska M, Rosen J, Gebbie $\mathrm{KM}$, et al. (2007) Non-hospital based registered nurses and the risk of bloodborne pathogen exposure. Ind Health 45: 695-704.

6. Butsashvili M, Kamkamidze G, Kajaia M, Morse DL, Triner W, et al. (2012) Occupational exposure to body fluids among health care workers in Georgia. Occup Med 62: 620-626.

7. Smith D, Richard W, Ning W, Rui S (2004) Needlesticks and sharps injuries among Chinese hospital nurses. Advances in Experimental Biology 7: 11-12.

8. Taiwan Needle Notification System, EPINET Chinese version.

9. Gabr HM, El-Badry AS, Younis FE (2018) Risk factors associated with needlestick injuries among health care workers in Menoufia Governorate, Egypt. Int J Occup Environ Med 9: 63-68.

10. Chen YC, Huang HM, Lin SL, Chou SS (2014) Breast cancer prevalence among nurses from the National Health Insurance Database. VGH Nursing 31: 186-195.

11. Chao TY, Huang JY, Chung $\mathrm{CH}$ (2013) Factors of medical cost among occupational injury inpatients. J Occup Saf Health 21: 415-431.

12. http://www.bli.gov.tw/reportY.aspx? $y=102 \& f=h 370$

13. http://www.bli.gov.tw/reportY.aspx?y=103\&f=h370

14. Raudenbush SW, Bryk AS (2002) Hierarchical linear models: Applications and data analysis methods. ( $2^{\text {nd }}$ edn), Sage, Newbury Park, CA.

15. Wu ML, Zhang Y (2014) Advanced applications of Multi-Level Models. Wu Nan, Taipei.

16. Cohen J (1988) Statistical power analysis for the behavioral sciences. ( $2^{\text {nd }}$ edn), Lawrence Erlbaum, New York.

17. Chou HJ, Wen FH (2007) Hierarchical linear modeling of contextual effects: An example of organizational climate of creativity at schools and teacher's creative performance. J Eddo Psychol 30: 1-35.

18. Cohen J (1998) Statistical power analysis for the behavioral sciences. ( $2^{\text {nd }}$ edn), Erlbaum, Hillsdale, NJ.

19. Chung YC, Hung CT, Li SF, Lee HM, Wang SG, et al. (2013) Risk of musculoskeletal disorder among Taiwanese nurses cohort: A nationwide population-based study. BMC Musculoskelet Disord 14: 144.

20. Chiu FW (2013) Occupational Accidents of Health Care Providers. School of Health Care Administration.

21. Shih KS, Lo JC (1996) A Study on the efficiency difference between public and private general hospitals. Chinese Journal of Public Health 15: 469-481.

22. Chen CY (2006) Exploring the Differences of customer satisfaction on service quality toward public and private hospitals using two regional hospitals as examples. National Central University.

23. Hsueh YS, Hung YS, Tang CH (2002) A national survey of physician-compensation arrangements at hospitals in Taiwan. Journal of Medical Education 6: 173-184.

24. Voide C, Darling KE, Kenfak-Foguena A, Erard V, Cavassini M, et al. (2012) Underreporting of needlestick and sharps injuries among healthcare workers in a swiss university hospital. Swiss Med Wkly 142: 13523.

25. Hu YJ (1984) An investigation on the lower back pain of nurses in public and private hospitals in Taichung City. Public Health 11: 6-16. 
26. Alamgir H, Yu S, Chavoshi N, Ngan K (2008) Occupational injury among full-time, part-time and casual health care workers. Occup Med 58: 348-354.

27. Kevorkyan AK, Petrova NS, Angelova NG (2012) A survey of occupational risk exposures and behavior of healthcare workers. Folia Med (Plovdiv) 54: 44-50.

28. Wang IK (2004) A study of coping strategies and perceived occupational hazards of psychiatric nurses in acute wards. Chung Shan Medical University.

29. Amin NA, Quek KF, Oxley JA, Noah R, Nordin R (2018) Emotional distress as a predictor of work-related musculoskeletal disorders in Malaysian nursing professionals. Int $\mathrm{J}$ Occup Environ Med 9: 69-78.

30. Liu LF, Lee S, Chia PF, Chi SC, Yin YC (2012) Exploring the association between nurse workload and nurse-sensitive patient safety outcome indicators. J Nurs Res 20: 300-309.
31. Harcombe H, Herbison GP, McBride D, Derrett S (2014) Musculoskeletal disorders among nurses compared with two other occupational groups. Occup Med (Lond) 64: 601607.

32. Berdahl TA, Marc Z (2010) Medical care utilization for work-related injuries in the United States 2002-2006. Med care 48: 645-651.

33. Umesh SR, David S, Segaran F, Venkatesh K (2014) Work-related health problems among nursing personnel. Nurs J India 105: 254-257.

34. Koo M, Lu MC, Tsai TY (2014) Secondary data analysis: research applications for healthcare providers. Formosan J Med 18: 471-479.

35. Robinson WS (2009) Ecological correlations and the behavior of individuals. Int J Epidemiol 38: 337-341. 